\title{
Online appointment booking 24/7
}

Did you know that online appointment booking is available for Dentally, which you can use to let your patients book 24/7 from your own website?

The portal has been specifically designed for Dentally; it allows patients to view and book appointments.

Dentally wants your dental practice to thrive; giving patients a way to manage their appointments is a small but essential part.

Today consumers can do pretty much everything online, whether it is to book a table for a restaurant, reserve cinema tickets, order a takeaway food delivery or book a taxi quickly - they easily can, anytime and anywhere. Why should booking appointments for dental treatment be any different? Introducing a feature on your website that is a secure patient portal, where a patient can view, book, reschedule or cancel appointments 24 hours a day, seven days per week

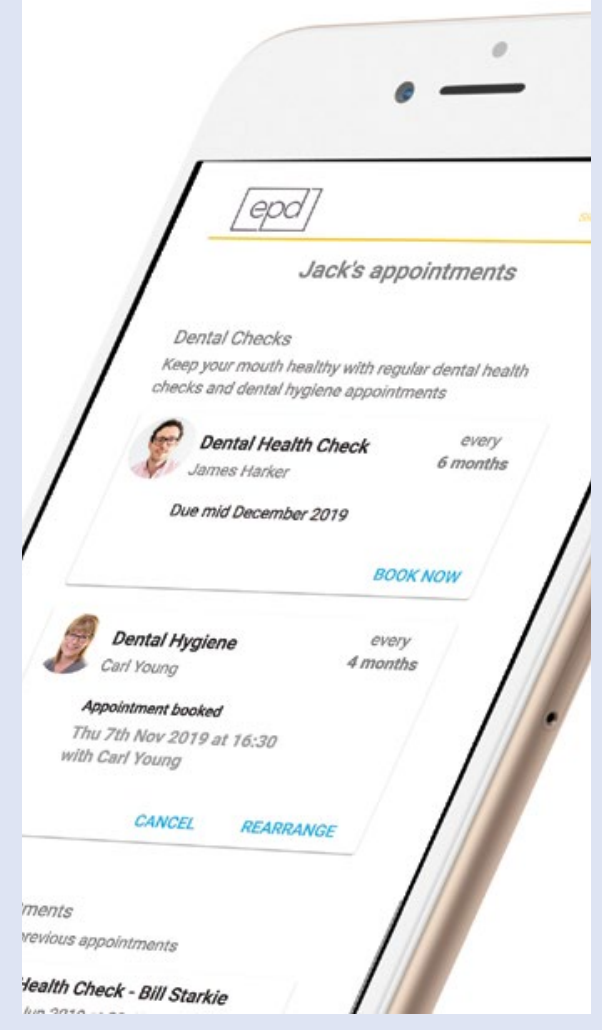

can only be beneficial to your dental practice.

It not only saves your patients time, thus helping you develop and maintain stronger patient relationships, but it can also save valuable surgery time by reducing missed appointments and it will free up time for your reception team.

The online appointment booking app for Dentally lets your patients book an appointment from your own practice website. A custom booking page can be shared or just add a 'Book' button to your site, ideal for existing patients and to attract new ones.

If you would like to learn more about online appointment booking and how you can add it to your website with a direct link to Dentally, then simply email hello@dentally.co or visit: https://dentally.co/integrations/ online-appointments.

\section{Cutting-edge, exciting equipment}

Are you excited for BDIA Dental Showcase 2019? W\&H certainly is! The manufacturer will be on stand $\mathrm{H} 21$ exhibiting its cutting-edge dental handpieces, surgical units, prophy product range, and decontamination equipment.

Delegates can look forward to live demonstrations of the new Osstell Beacon, which can be used to measure implant stability. In addition, the expert team will be on-hand to discuss the benefits of the Piezomed and the Implantmed with its innovative ISQ module.

Among W\&H's other offerings is the new prophylaxis product range, featuring the Proxeo TWIST Cordless, the Proxeo Aura air polishing system, and Proxeo Ultra piezo scalers, which are suitable for use on patients with pacemakers. W\&H will also be showcasing the new Lisa and Lara sterilisers, which are designed to streamline the decontamination workflow.

Visit www.wh.com/en_uk, call 01727 874990 or email office.uk@wh.com.

\section{Dental magnification and illumination}

Will you be at BDIA Dental Showcase 2019? Nuview is looking forward to meeting delegates on stand N70, where the friendly team will be showcasing the advanced Carl Zeiss dental magnification and illumination equipment they supply.

These include the innovative EXTARO 300 dental microscope - featuring several breakthrough visualisation modes - as well as the EyeMag Pro and Eye Mag Smart dental loupes, which boast superior optics. Nuview will also be on hand to discuss the benefits of its Continu range of alcohol-free, water-based cleaning and disinfectant products.

Join Nuview at this year's BDIA Dental Showcase to take advantage of exclusive offers. You won't want to miss out!

For more information call Nuview on 01453 872266, email info@nuview-ltd.com, visit www.nuview.co or 'like' Nuview on Facebook.

\section{Adhesive ease}

Fitting orthodontic brackets accurately can be difficult, especially if you're using brackets that don't give you a helping hand.

Ensure precise bracket placement with the APC II Adhesive Appliance System from 3M Oral Care.

An innovative way to achieve excellent orthodontic results, the system has improved on the previous formula in a number of ways, not only by being lighter and less viscous but also soft enough to ensure accurate placement.
In addition, the adhesive formula provides a strong hold that helps eliminate bracket drift and excessive flash, helping professionals to achieve predictable results every time.

Discover the APC II Adhesive Appliance System to see how it can benefit your patients. For more information, call 0845 8734066 or visit http://solutions.3m.co.uk/ wps/portal/3M/en_GB/orthodontics_EU/ Unitek/

$3 \mathrm{M}$ and APC II are trademarks of the 3M Company. 